\title{
Posttraumatic complications in pediatric skull fracture: dural sinus thrombosis, arterial dissection, and cerebrospinal fluid leakage
}

\author{
Adedamola Adepoju, MD, and Matthew A. Adamo, MD \\ Department of Neurosurgery, Albany Medical College, Albany, New York
}

OBJECTIVE Skull fracture is associated with several intracranial injuries. The object of this study was to determine the rate of fracture associated with venous thrombosis, intracranial arterial dissection (ICAD), and cerebrospinal fluid (CSF) leakage in pediatric patients. Further, the authors aimed to highlight the features of pediatric skull fracture that predict poor neurological outcomes.

METHOD In this retrospective study, the authors evaluated the records of 258 pediatric patients who had incurred a traumatic skull fracture in the period from 2009 to 2015 . All the patients had undergone CT imaging, which was used to characterize the type of skull fracture and other important features, including intracranial hemorrhage. Patients with fracture extending to a dural sinus or proximal to major intracranial vessels had undergone vascular imaging to evaluate for venous thrombosis or arterial dissection. Clinical data were also reviewed for patients who had CSF leakage.

RESULTS Two hundred fifty-eight patients had 302 skull fractures, with $11.6 \%$ having multiple fractures. Falling was the most common mechanism of injury (52.3\%), and the parietal bone was most frequently involved in the fracture (43.4\%). Diastatic fracture was associated with increased intracranial hemorrhage $(p<0.05)$. The rate of venous thrombosis was $0.4 \%$, and the rate of ICAD was also $0.4 \%$. The rate of CSF leakage was $2.3 \%$. Skull base fracture was the only significant risk factor associated with an increased risk of CSF leakage $(p<0.05)$. There was a significant difference in fracture-related morbidity in patients younger than versus older than 2 years of age. Patients younger than 2 years had fewer intracranial hemorrhages ( $21.8 \%$ vs $38.8 \%$ ) and fewer neurosurgical interventions ( $3.0 \%$ vs $12.7 \%$ ) than the patients older than 2 years $(p<0.001)$. Moreover, skull fracture in the younger group was mostly caused by falling $(81.2 \%$ vs $33.1 \%)$; in the older group, fracture was most often caused by vehicle-related accidents (35.7\% vs $4.0 \%$ ) and being struck by or against an object (19.1\% vs $7.9 \%$ ). Additionally, skull fracture location was analyzed based on the mechanism of injury. Parietal bone fracture was closely associated with falling, and temporal bone fracture was associated with being struck by or against an object $(p<0.05)$. Frontal bone fracture was more associated with being struck by or against an object and vehicle-related injury $(p<0.05)$ than with falling. Vehicle-related accidents and being struck by or against an object, as opposed to falling, were associated with increased surgical intervention ( $13.3 \%$ vs $16.2 \%$ vs $3.7 \%$, respectively).

CONCLUSIONS Pediatric skull fracture usually has a benign outcome in patients who fall and are younger than 2 years of age. Poor prognostic factors include diastasis, an age $>2$ years, and fracture caused by vehicle-related accidents or being struck by or against an object. In this series, the rates of venous thrombosis and ICAD were low, and the authors do not advocate vascular imaging unless these disease entities are clinically suspected. Patients with skull base fracture should be closely monitored for CSF leakage.

https://thejns.org/doi/abs/10.3171/2017.6.PEDS16702

KEY WORDS pediatric skull fracture; dural sinus thrombosis; arterial dissection; cerebrospinal fluid leak; trauma

$\mathrm{S}$ KULL fracture is a common feature of traumatic head injury in the pediatric population $(6.2 \%-10 \%$ of cases per year) and is a major cause of morbidity and mortality. ${ }^{1,4,8,18}$ Technological advances in imaging have allowed us to delineate risk factors associated with severe head injury, and skull fracture is an important clinical finding in the evaluation of patients with traumatic injury. 2,16,17,22 Pediatric patients, especially neonates, commonly present with skull fracture from either a low-impact injury, such as falling from a low height, or a high-impact injury, such as a vehicle-related accident. Pediatric patients are managed aggressively and sometimes require neurosurgical treatment. ${ }^{2,14,15}$

Skull fracture is an independent risk factor for the de-

ABBREVIATIONS CSF = cerebrospinal fluid; $C T A=C T$ angiography; $G C S=$ Glasgow Coma Scale; ICAD = intracranial arterial dissection; MRA = MR angiography . SUBMITTED January 17, 2017. ACCEPTED June 16, 2017.

INCLUDE WHEN CITING Published online October 13, 2017; DOI: 10.3171/2017.6.PEDS16702. 
velopment of intracranial hemorrhage, which can worsen the neurological outcome in patients with traumatic brain injury. ${ }^{71}$ In addition to the intracranial hemorrhage, skull fractures can be associated with less commonly identifiable injuries such as venous thrombosis, intracranial arterial dissection (ICAD), and cerebrospinal fluid (CSF) leakage. ${ }^{6,9,10,13,19,21,23-25}$ The occurrence of these injuries has been studied in adult patients but not in pediatric patients. Venous thrombosis and ICAD can worsen neurological outcome with ischemia and hemorrhage, respectively. Cerebrospinal fluid leakage is also a risk factor for posttraumatic meningitis., ${ }^{9,11,20}$ The objectives of this study were to delineate the rate of venous thrombosis, ICAD, and CSF leakage in the pediatric population with skull fracture. In addition, we wanted to determine the factors predictive of a poor neurological outcome in pediatric patients with skull fractures.

\section{Methods}

We obtained approval from the institutional review board at Albany Medical College to retrospectively review the records of patients younger than 18 years old who had incurred traumatic skull fracture in the period from July 2009 to August 2015. Patients with traumatic head injury had undergone noncontrast CT scanning as part of the trauma evaluation based on their clinical presentation. The radiological imaging was reviewed by one of three neuroradiologists in the Department of Radiology at our institution, and they provided reports that we used for our study. Patients with skull fracture are immediately evaluated and treated by the neurosurgical team at our institution. This study included patients with linear fracture, depressed fracture (fragments infolded toward the brain), basilar skull fracture, and diastatic fracture. Single fractures extending across sutures into adjacent bones were considered single, rather than multiple, in classification. Venous thrombosis and ICAD were diagnosed with vascular imaging, which mainly consisted of CT angiography (CTA) or MR angiography (MRA). We determined the number of patients who had CSF leakage based on the clinical examination or laboratory study.

Two hundred sixty-four patients qualified for this study, but 4 patients were discharged or transferred to another facility from the emergency department and were not admitted to our institution. There were no clinical data about these patients; thus, they were excluded from our study. The remaining 260 patients were included in this study. We determined the demographics for this group, including the mean age, median age, and sex. We used the Centers for Disease Control and Prevention (CDC) classification to group mechanisms of injury, which includes falls, vehiclerelated accidents, being struck by or against an object, assaults, and unknown..$^{12}$ Of importance, pedestrian accidents were grouped under the mechanism of being struck by or against an object. We also included in the study sportsrelated injuries such as those occurring while skiing, sledding, diving, and undertaking other sports activities.

We classified patients based on the number of fractures incurred (single vs multiple), type of fracture, mechanism of injury, fracture sites, presence of intracranial hemorrhage, and Glasgow Coma Scale (GCS) score at the initial presentation. Single linear fractures that branched from a point into separate linear fractures were classified as multiple fractures. Only patients who had undergone craniotomy or craniectomy were classified as having received neurosurgical treatment. Conservative management consisted of accepted medical therapy, including appropriate administration of anticoagulation or antiplatelet agents or other medical therapies as indicated, as well as intracranial monitoring, external ventricular drainage, or lumbar puncture or drain.

We used the chi-square test to determine statistical significance in our study. A $p$ value $<0.001$ was considered significant.

\section{Results}

During the study period, 258 patients $(60.5 \%$ male, $39.5 \%$ female) presented with 302 skull fractures (Table 1). The mean age was 6.95 years and the median was 6.0 years. Approximately $39.1 \%$ of the patients were younger than 2 years of age. The main mechanism of injury was falling (52.3\%), followed by vehicle-related accident (23.3\%), being struck by or against an object (14.3\%), an assault (4.3\%), and sports-related injury (3.9\%). We could not account for cause of injury in $1.9 \%$ of the patients. Most of the patients had moderate to mild head injury with an initial GCS score $>9$ in $89.2 \%$. The majority of skull fractures were linear (84.1\%), and depressed fractures occurred in $9.9 \%$ of cases. About $6.0 \%$ of the cases were diastasis fractures. The parietal bone was the most common fracture site $(43.4 \%)$, followed by the temporal bone $(30.6 \%)$ and frontal bone $(24.0 \%)$. Occipital and skull base fractures occurred in $20.9 \%$ and $17.8 \%$ of the patients, respectively. About $32.2 \%$ of the patients had an intracranial hemorrhage, of which epidural and subdural hematomas were present equally (approximately 14\% each). Subarachnoid and intraparenchymal hemorrhages occurred in $11.2 \%$ and $7.8 \%$ of patients, respectively. The majority of patients (57.1\%) had more than one type of intracranial hemorrhage (data not shown).

Thirty patients (11.6\%) had more than 1 fracture, with 8 patients in this group having more than 2 fractures. There was no statistical association between mechanism of injury and multiple skull fractures (Table 2). Multiple fractures were associated with increased diastasis $(20 \%$ vs $5.3 \%$, p $<0.01$ ) but not with depressed fracture. Depressed skull fracture was more prominent in the single-fracture group (11.8\% vs $10 \%)$ but not at a statistically significant level. Multiple fractures were associated with severe head injury as identified by an initial GCS Score $3-8(30.0 \%$ vs $8.3 \%$, $\mathrm{p}<0.05$ ), but the rate of intracranial hemorrhage was similar in the 2 groups (33.3\% vs 32.0\%). More patients with multiple fractures required neurosurgical treatment $(16.7 \%$ vs $7.9 \%$ ) but there was no statistical difference between the 2 groups. Sixteen patients $(6.2 \%)$ had diastatic fractures (Table 3), and we compared this group to patients without diastatic fracture. There was no significant association between mechanism of injury and diastatic fracture. Although diastatic fracture was associated with increased intracranial hemorrhage $(\mathrm{p}<0.05)$, none of the patients with such fractures required neurosurgical intervention. 
TABLE 1. Demographics of patients with skull fractures

\begin{tabular}{|c|c|c|}
\hline Parameter & No. & $\%$ \\
\hline No. of patients & 258 & \\
\hline Female & 102 & 39.5 \\
\hline Male & 156 & 60.5 \\
\hline \multicolumn{3}{|l|}{ Age in yrs } \\
\hline Mean & 6.95 & \\
\hline Median & 6.00 & \\
\hline \multicolumn{3}{|l|}{ Mechanism of injury } \\
\hline Fall & 135 & 52.3 \\
\hline Vehicle related & 60 & 23.2 \\
\hline Struck by or against an object & 37 & 14.3 \\
\hline Assault & 11 & 4.3 \\
\hline Sports related & 10 & 3.9 \\
\hline Unknown & 5 & 1.9 \\
\hline \multicolumn{3}{|l|}{ Initial GCS score } \\
\hline $3-8$ & 28 & 10.8 \\
\hline $9-12$ & 20 & 7.8 \\
\hline $13-15$ & 210 & 81.4 \\
\hline Total fxs & 302 & \\
\hline Depressed fx & 30 & 9.9 \\
\hline Linear $\mathrm{fx}$ & 254 & 84.1 \\
\hline Diastasis & 18 & 6.0 \\
\hline Patients $\mathrm{w} />1 \mathrm{fx}$ & 30 & 11.6 \\
\hline \multicolumn{3}{|l|}{ Fx involving } \\
\hline Frontal bone & 62 & 24.0 \\
\hline Parietal bone & 112 & 43.4 \\
\hline Temporal bone & 79 & 30.6 \\
\hline Occipital bone & 54 & 20.9 \\
\hline Skull base & 46 & 17.8 \\
\hline Fx involving venous sinus & 6 & 2.3 \\
\hline Pneumocephalus & 49 & 19.0 \\
\hline $\mathrm{ICH}$ & 83 & 32.2 \\
\hline Venous thrombosis & 1 & 0.4 \\
\hline Surgical treatment & 23 & 8.9 \\
\hline CSF leakage & 6 & 2.3 \\
\hline Arterial dissection & 1 & 0.4 \\
\hline
\end{tabular}

$\mathrm{fx}=$ fracture; $\mathrm{ICH}=$ intracranial hemorrhage.

We compared the patients with the 3 most common mechanisms of injury: fall, vehicle related, and struck by or against an object (Table 4). One hundred thirty-five patients had presented with a fall, 60 with a vehicle-related injury, and 37 had been struck by or against an object. Parietal bone fracture was more common in the fall group $(52.6 \%)$ than in the groups with vehicle-related accidents $(38.3 \%)$ or those struck by or against an object $(27.0 \%)$. Conversely, frontal bone fracture was more common in the vehicle-related group (35.0\%) and the struck group $(29.7 \%)$ than in the fall group (18.5\%). Temporal bone fracture was most common in the struck group (59.4\%). These findings were statistically significant $(\mathrm{p}<0.05)$. Severe head injury based on an initial GCS score of 3-8 was more often associated with vehicle-related injury $(25.0 \%$
TABLE 2. Comparison of patients with multiple versus single skull fractures

\begin{tabular}{|c|c|c|c|c|c|}
\hline \multirow[b]{2}{*}{ Parameter } & \multicolumn{2}{|c|}{$>1 \mathrm{Fx}$} & \multicolumn{2}{|c|}{$1 \mathrm{Fx}$} & \multirow{2}{*}{$\begin{array}{c}p \\
\text { Value }\end{array}$} \\
\hline & No. & $\%$ & No. & $\%$ & \\
\hline Total no. of patients & 30 & 11.6 & 228 & 88.4 & \\
\hline Mean age in yrs & 8.52 & & 6.7 & & \\
\hline \multicolumn{6}{|l|}{ No. of patients } \\
\hline Female & 12 & 40.0 & 90 & 39.5 & \\
\hline Male & 18 & 60.0 & 138 & 60.5 & \\
\hline \multicolumn{6}{|l|}{ Mechanism of injury } \\
\hline Fall & 13 & 43.3 & 122 & 53.5 & 0.294 \\
\hline Vehicle related & 9 & 30.0 & 55 & 24.1 & 0.484 \\
\hline $\begin{array}{l}\text { Struck by or against } \\
\text { an object }\end{array}$ & 5 & 16.7 & 28 & 12.3 & \\
\hline Assault & 1 & 3.3 & 10 & 4.4 & \\
\hline Sports related & 2 & 6.7 & 8 & 3.5 & \\
\hline Unknown & 0 & 0.0 & 5 & 2.2 & \\
\hline Depressed fx & 3 & 10.0 & 27 & 11.8 & 0.767 \\
\hline Diastasis $\mathrm{fx}$ & 6 & 20.0 & 12 & 5.3 & $<0.01$ \\
\hline \multicolumn{6}{|l|}{ Initial GCS score } \\
\hline $3-8$ & 9 & 30.0 & 19 & 8.3 & $<0.01$ \\
\hline $9-12$ & 6 & 20.0 & 14 & 6.1 & \\
\hline $13-15$ & 15 & 50.0 & 195 & 85.5 & \\
\hline $\mathrm{ICH}$ & 10 & 33.3 & 73 & 32.0 & 0.885 \\
\hline Surgical treatment & 5 & 16.7 & 18 & 7.9 & 0.113 \\
\hline
\end{tabular}

vs $6.7 \%$ in the fall group and $5.4 \%$ in the struck group, $\mathrm{p}$ $<0.05)$. The struck group had a significant increase in intracranial hemorrhage compared with the vehicle-related and fall groups (37.8\% vs $10.0 \%$ and $4.4 \%$, respectively, $\mathrm{p}$ $<0.05)$. The need for neurosurgical treatment was more common in the struck group (16.2\%) and vehicle-related group $(13.3 \%)$ than in the fall group $(3.7 \%$; $p<0.05)$. Thus, vehicle-related accidents and being struck by or against an object were associated with intracranial hemorrhage and the need for neurosurgical treatment.

About $40 \%$ of the study group was under 2 years of age, and they tended to present with low-impact injuries. We divided the patients into 2 groups according to ageyounger than 2 versus older than 2 -to determine if there was a difference between the two (Table 5). Falling was the major cause of skull fracture in the group younger than $2(81.2 \%$ vs $33.1 \%)$, whereas vehicle-related accidents (35.7\% vs $4.0 \%$ ) and being struck by or against an object $(19.1 \%$ vs $7.9 \%)$ were major causes of injury in the group older than $2(p<0.001)$. The younger group had more parietal fractures than the older group (70.3\% vs $26.1 \%)$. The latter group had more frontal (29.9\% vs $14.8 \%)$, temporal (36.3\% vs $21.8 \%)$, and skull base $(25.5 \%$ vs $5.9 \%)$ fractures than the former group $(\mathrm{p}<0.001)$. Severe head injury as indicated by an initial GCS Score 3-8 was more common in the older group ( $15.3 \%$ vs $4.0 \%)$, as was increased intracranial hemorrhage $(38.85 \%$ vs $21.78 \%, \mathrm{p}<0.001)$. Furthermore, the older group had neurosurgical treatment more often than the younger group $(12.7 \%$ vs $3.0 \%$, p < 0.001). In sum, skull fracture in patients older than 2 years 
TABLE 3. Comparison of patients with diastatic and nondiastatic skull fractures

\begin{tabular}{|c|c|c|c|c|c|}
\hline \multirow[b]{2}{*}{ Parameter } & \multicolumn{2}{|c|}{ Diastatic Fx } & \multicolumn{2}{|c|}{ Nondiastatic Fx } & \multirow{2}{*}{$\begin{array}{c}p \\
\text { Value }\end{array}$} \\
\hline & No. & $\%$ & No. & $\%$ & \\
\hline No. of patients & 16 & 6.2 & 242 & 93.8 & \\
\hline \multicolumn{6}{|l|}{ Mechanism of injury } \\
\hline Fall & 6 & 37.5 & 129 & 53.3 & 0.220 \\
\hline Vehicle related & 6 & 37.5 & 54 & 22.3 & 0.164 \\
\hline $\begin{array}{l}\text { Struck by or against } \\
\text { an object }\end{array}$ & 4 & 25.0 & 33 & 13.6 & 0.209 \\
\hline Assault & 0 & 0.0 & 11 & 4.5 & \\
\hline Sports related & 0 & 0.0 & 10 & 4.1 & \\
\hline Unknown & 0 & 0.0 & 5 & 2.1 & \\
\hline \multicolumn{6}{|l|}{ Initial GCS score } \\
\hline $3-8$ & 3 & 18.8 & 25 & 10.3 & 0.294 \\
\hline $9-12$ & 2 & 12.5 & 18 & 7.4 & \\
\hline $13-15$ & 11 & 68.8 & 199 & 82.2 & 0.180 \\
\hline $\mathrm{ICH}$ & 9 & 56.2 & 74 & 30.6 & 0.033 \\
\hline Surgical treatment & 0 & 0.0 & 0 & 0.0 & \\
\hline Depressed & 0 & 0.0 & 30 & 12.4 & \\
\hline
\end{tabular}

is more frequently associated with severe head injury, increased intracranial hemorrhage, and the need for neurosurgical treatment.

We also looked into 2 unrelated types of vascular injuries in patients with skull fractures: ICAD and venous thrombosis. Six patients had fractures extending to a dural sinus, and 12 patients had fractures that crossed the path of a major intracranial artery (that is, a skull base fracture extending to the petrosal canal involving the internal carotid artery). These patients had vascular imaging (CTA or MRA), and 1 patient each had ICAD and venous thrombosis, resulting in a $0.4 \%$ incidence rate for each injury (Table 1). The patient with arterial dissection was a 17-year-old female who had been involved in a pedestrian accident and presented with multiple fractures including skull base fracture. There was no intracranial hemorrhage or ischemia. The other patient with venous thrombosis sustained an injury while falling from a moving vehicle, and he had a linear fracture that extended over the transverse sinus. He had a small extraaxial hemorrhage around the transverse sinus with extensive pneumocephalus tracking from the transverse to sigmoid sinuses. The extraaxial hematoma worsened, and the patient eventually required neurosurgical treatment.

Six patients (2.3\%) developed CSF leakage, and 1 of these patients (16.7\%) developed posttraumatic meningitis (Table 6). About $80 \%$ of the CSF leakage occurred proximal to a fracture site. In one instance, fracture involving the petrous bone was associated with otorrhea and fracture involving the anterior skull base was associated with rhinorrhea. Fifty percent of these patients had skull base fracture, and it was the most significant fracture associated with CSF leakage $(p<0.05)$. Fifty percent had pneumocephalus, which could suggest a possible connection between the intracranial and extracranial space; however, the association between pneumocephalus and CSF leak-
TABLE 4. Analysis of patients with skull fractures based on mechanism of injury

\begin{tabular}{|c|c|c|c|c|c|c|c|}
\hline \multirow[b]{2}{*}{ Parameter } & \multicolumn{2}{|c|}{ Fall } & \multicolumn{2}{|c|}{$\begin{array}{c}\text { Vehicle- } \\
\text { Related } \\
\text { Injury }\end{array}$} & \multicolumn{2}{|c|}{$\begin{array}{l}\text { Struck by } \\
\text { or Against } \\
\text { an Object }\end{array}$} & \multirow{2}{*}{$\begin{array}{c}p \\
\text { Value }\end{array}$} \\
\hline & No. & $\%$ & No. & $\%$ & No. & $\%$ & \\
\hline Total no. of patients & 135 & 52.3 & 60 & 23.3 & 37 & 14.3 & \\
\hline Female & 60 & 44.4 & 15 & 25.0 & 16 & 43.2 & \\
\hline Male & 75 & 55.6 & 45 & 75.0 & 21 & 56.8 & \\
\hline \multicolumn{8}{|l|}{ Age in yrs } \\
\hline Mean & \multicolumn{2}{|l|}{3.9} & \multicolumn{2}{|l|}{12.5} & \multicolumn{2}{|l|}{9.1} & \\
\hline SD & \multicolumn{2}{|l|}{4.8} & \multicolumn{2}{|l|}{4.6} & \multicolumn{2}{|l|}{5.5} & \\
\hline \multicolumn{8}{|l|}{ Fx site } \\
\hline Frontal & 25 & 18.5 & 21 & 35.0 & 11 & 29.7 & $<0.05$ \\
\hline Parietal & 71 & 52.6 & 23 & 38.3 & 10 & 27.0 & $<0.05$ \\
\hline Temporal & 24 & 17.8 & 13 & 21.7 & 22 & 59.4 & $<0.05$ \\
\hline Occipital & 31 & 23.0 & 17 & 28.3 & 5 & 13.5 & \\
\hline Skull base & 19 & 14.1 & 16 & 26.7 & 8 & 21.6 & \\
\hline \multicolumn{8}{|l|}{ Initial GCS score } \\
\hline $3-8$ & 9 & 6.7 & 15 & 25.0 & 2 & 5.4 & $<0.05$ \\
\hline $9-12$ & 2 & 1.5 & 7 & 11.7 & 7 & 18.9 & \\
\hline $13-15$ & 124 & 91.8 & 38 & 63.3 & 28 & 75.7 & \\
\hline $\mathrm{ICH}$ & 6 & 4.4 & 6 & 10.0 & 14 & 37.8 & $<0.05$ \\
\hline Surgical treatment & 5 & 3.7 & 8 & 13.3 & 6 & 16.2 & $<0.05$ \\
\hline
\end{tabular}

age in patients with skull fracture was not statistically significant. As indicated, the rate of posttraumatic meningitis was $16.7 \%$ among the patients with CSF leakage. However, the number of patients with meningitis was not adequate to determine the significance of posttraumatic meningitis.

\section{Discussion}

This was a retrospective study to determine the rate of ICAD, dural sinus thrombosis, and CSF leakage in pediatric patients with skull fracture. It was a moderately sized study, and our analysis showed that the majority of patients with skull fracture had a good neurological presentation and outcome, with about one-third having an intracranial hemorrhage and less than $10 \%$ requiring neurosurgical intervention. Our data support the findings in other studies that have indicated that falling is the most common cause of injury and that the parietal bone is the most common location for skull fracture. ${ }^{1,5,12}$ Our rates of arterial dissection and venous sinus thrombosis were $0.4 \%$ each, and the rate of CSF leakage was $2.33 \%$.

Patients younger than 2 years old, who are more likely to present with a low-impact injury, were compared with patients older than 2 . There was a significant difference between these two groups. Falling was the major mechanism of injury in the younger group, whereas fracture due to vehicle-related accidents and being struck by or against an object were common in the older group. Similarly, the site of skull fracture was different between the two groups. Parietal bone fracture was prominent in the younger group, while frontal bone, temporal bone, and skull base fractures were common in the older group. 
TABLE 5. Comparison of patients older or younger than 2 years

\begin{tabular}{|c|c|c|c|c|c|}
\hline \multirow[b]{3}{*}{ Parameter } & \multicolumn{4}{|c|}{ Age in Years } & \multirow{3}{*}{$\begin{array}{c}p \\
\text { Value }\end{array}$} \\
\hline & \multicolumn{2}{|c|}{$>2$} & \multicolumn{2}{|c|}{$<2$} & \\
\hline & No. & $\%$ & No. & $\%$ & \\
\hline No. of patients & 157 & 60.8 & 101 & 39.1 & \\
\hline Female & 102 & 65.0 & 47 & 46.5 & \\
\hline Male & 55 & 35.0 & 54 & 53.5 & \\
\hline \multicolumn{6}{|l|}{ Mechanism of injury } \\
\hline Fall & 52 & 33.1 & 82 & 81.2 & $<0.001$ \\
\hline Vehicle related & 57 & 35.7 & 4 & 4.0 & $<0.001$ \\
\hline Struck by or against an object & 30 & 19.1 & 8 & 7.9 & $<0.001$ \\
\hline Assault & 8 & 4.5 & 2 & 2.0 & \\
\hline Sports related & 8 & 5.1 & 0 & 0.0 & \\
\hline Unknown & 2 & 1.3 & 5 & 5.9 & \\
\hline \multicolumn{6}{|l|}{ Initial GCS score } \\
\hline $3-8$ & 24 & 15.3 & 4 & 4.0 & $<0.001$ \\
\hline $9-12$ & 17 & 10.8 & 2 & 2.0 & \\
\hline $13-15$ & 116 & 74.5 & 95 & 95.0 & \\
\hline Total fxs & 189 & & 113 & & \\
\hline Depressed fx & 17 & 9.0 & 13 & 11.5 & $<0.001$ \\
\hline Linear $\mathrm{fx}$ & 158 & 83.6 & 96 & 85.8 & \\
\hline Diastasis & 14 & 7.4 & 4 & 3.5 & $<0.001$ \\
\hline No. of patients $w />1 \mathrm{fx}$ & 18 & 11.5 & 12 & 11.9 & $<0.001$ \\
\hline \multicolumn{6}{|l|}{ Fx site involving } \\
\hline Frontal & 47 & 29.9 & 15 & 14.8 & $<0.001$ \\
\hline Parietal & 41 & 26.1 & 71 & 70.3 & $<0.001$ \\
\hline Temporal & 57 & 36.3 & 22 & 21.8 & $<0.001$ \\
\hline Occipital & 38 & 24.2 & 16 & 15.8 & $<0.001$ \\
\hline Skull base & 40 & 25.5 & 6 & 5.9 & $<0.001$ \\
\hline Pneumocephalus & 42 & 26.8 & 7 & 6.9 & $<0.001$ \\
\hline Fx involving venous sinus & 3 & 1.9 & 3 & 3.0 & \\
\hline $\mathrm{ICH}$ & 61 & 38.8 & 22 & 21.8 & $<0.001$ \\
\hline Venous thrombosis & 1 & 0.6 & 0 & 0.0 & \\
\hline Surgical treatment & 20 & 12.7 & 3 & 3.0 & $<0.001$ \\
\hline CSF leakage & 6 & 3.8 & 0 & 0.0 & \\
\hline Arterial dissection & 1 & 0.6 & 0 & 0.0 & \\
\hline
\end{tabular}

Furthermore, the older patients had a poorer neurological presentation, had a higher rate of intracranial hemorrhage, and required neurosurgical intervention more often. A possible mechanism to explain the differences between the two age groups could be related to differences in the mechanism of injury. Vehicle-related accidents and being struck by or against an object, which were the most common mechanisms of injury in the patients older than 2 years, were associated with increased intracranial hemorrhage and neurosurgical intervention.

Patients can present with multiple skull fractures and diastatic fractures in the setting of high-impact injuries. It is appropriate to assume that these fractures could be associated with an increased risk of intracranial injury. Our data showed that the presence of multiple fractures was associated with a poor neurological presentation but did not increase the risk of intracranial hemorrhage or neurosurgi-
TABLE 6. Analysis of patients with skull fractures associated with CSF leakage

\begin{tabular}{lccc}
\hline \multicolumn{1}{c}{ Parameter } & No. & $\%$ & p Value \\
\hline Total no. of patients & 6 & & \\
\hline Age in yrs & & & \\
\hline Mean & 12.5 & & \\
\hline Median & 13.0 & & \\
\hline Mechanism of injury & & & \\
\hline Fall & 2 & 33.3 & \\
\hline Vehicle related & 3 & 50.0 & \\
\hline Struck by or against an object & 1 & 16.7 & \\
\hline Initial GCS score & & & \\
\hline 3-8 & 0 & 0.0 & \\
\hline 9-12 & 1 & 16.7 & \\
\hline 13-15 & 5 & 83.3 & \\
\hline Fx involving & & & \\
\hline Frontal bone & 2 & 33.3 & \\
\hline Parietal bone & 0 & 0.0 & \\
\hline Temporal bone & 0 & 0.0 & \\
\hline Occipital bone & 1 & 16.7 & \\
\hline Skull base alone & 3 & 50.0 & 0.02 \\
\hline Diastasis & 2 & 33.3 & \\
\hline Depressed fx & 0 & 0.0 & \\
\hline Pneumocephalus & 3 & 50.0 & 0.05 \\
\hline Meningitis & 1 & 16.7 & \\
\hline
\end{tabular}

cal treatment, compared with a single skull fracture. On the other hand, a diastatic fracture was associated with a higher incidence of intracranial hemorrhage than a nondiastatic fracture, but the patients with a diastatic fracture did not require surgical intervention. The opening of the suture line probably reduces intracranial pressure and hence minimizes the need for surgical decompression for cerebral edema associated with severe traumatic brain injury.

Our study showed that the rate of skull fracture-associated venous thrombosis or ICAD in pediatric patients was low at $0.4 \%$. No further neurological injury was associated with the dissection. However, we did not have a large enough sample size to determine the significance of neurological deficits associated with traumatic ICAD. Conversely, the rate of venous thrombosis was low, but the patient developed further complications from anticoagulation, which required surgical intervention. Again, the sample size was too small to statistically determine the significance of venous thrombosis, but this study suggests that venous thrombosis could be associated with a worse outcome. A large study would be required to determine the natural history of skull fractures associated with venous thrombosis and to evaluate the best way to manage these patients and optimize clinical outcomes.

The overall rate of CSF leakage was low in our pediatric skull fracture population, compared with the rate in adult patients with skull fracture. Our data showed a 2.3\% rate of CSF leakage, which is lower than the 4.6\%-11.5\% rate in the adult population. ${ }^{3,6}$ It is possible that the adult group sustained more severe injuries compared with the 
injuries in the pediatric group. Our rate of posttraumatic meningitis was $16.7 \%$, which was due to delayed CSF leakage. Skull base fracture was the only statistically significant risk factor associated with CSF leakage. The presence of pneumocephalus was associated with an increased rate of CSF leakage, but was not statistically significant. A large study would provide more information about other factors associated with CSF leakage and how pediatric patients should be managed, but our work is a promising step to expand on and improve the treatment of traumatic head injury in pediatric patients.

\section{Conclusions}

In sum, skull fractures in pediatric patients are common in the setting of trauma; however, the rate of significant neurological morbidity is low except when the fracture is associated with skull base and diastatic fractures. In addition, fractures caused by vehicle-related accidents or being struck by or against an object are associated with worse outcomes. Further, our series showed that although the rate of ICAD is low, if this injury is suspected based on clinical examination or if a fracture crosses a sinus or the carotid canal, then vessel imaging with CTA or CT venography is appropriate. Further, clinical suspicion should be high for CSF leakage in pediatric patients with skull base fracture.

\section{References}

1. Alexiou GA, Sfakianos G, Prodromou N: Pediatric head trauma. J Emerg Trauma Shock 4:403-408, 2011

2. Arrey EN, Kerr ML, Fletcher S, Cox CS Jr, Sandberg DI: Linear nondisplaced skull fractures in children: who should be observed or admitted? J Neurosurg Pediatr 16:703-708, 2015

3. Bell RB, Dierks EJ, Homer L, Potter BE: Management of cerebrospinal fluid leak associated with craniomaxillofacial trauma. J Oral Maxillofac Surg 62:676-684, 2004

4. Berger MS, Pitts LH, Lovely M, Edwards MS, Bartkowski HM: Outcome from severe head injury in children and adolescents. J Neurosurg 62:194-199, 1985

5. Bonfield CM, Naran S, Adetayo OA, Pollack IF, Losee JE: Pediatric skull fractures: the need for surgical intervention, characteristics, complications, and outcomes. J Neurosurg Pediatr 14:205-211, 2014

6. Brawley BW, Kelly WA: Treatment of basal skull fractures with and without cerebrospinal fluid fistulae. J Neurosurg 26:57-61, 1967

7. Chan KH, Mann KS, Yue CP, Fan YW, Cheung M: The significance of skull fracture in acute traumatic intracranial hematomas in adolescents: a prospective study. J Neurosurg 72:189-194, 1990

8. Dacey RG Jr, Alves WM, Rimel RW, Winn HR, Jane JA: Neurosurgical complications after apparently minor head injury. Assessment of risk in a series of 610 patients. J Neurosurg 65:203-210, 1986

9. Dagi TF, Meyer FB, Poletti CA: The incidence and prevention of meningitis after basilar skull fracture. Am J Emerg Med 1:295-298, 1983

10. Delgado Almandoz JE, Kelly HR, Schaefer PW, Lev MH, Gonzalez RG, Romero JM: Prevalence of traumatic dural venous sinus thrombosis in high-risk acute blunt head trauma patients evaluated with multidetector CT venography. Radiology 255:570-577, 2010

11. Eftekhar B, Ghodsi M, Nejat F, Ketabchi E, Esmaeeli B: Prophylactic administration of ceftriaxone for the prevention of meningitis after traumatic pneumocephalus: results of a clinical trial. J Neurosurg 101:757-761, 2004

12. Faul M, Xu L, Wald MM, Coronado V, Dellinger AM: Traumatic brain injury in the United States: national estimates of prevalence and incidence, 2002-2006. Inj Prev 16:A268, 2010 (Abstract)

13. Fujii Y, Tasaki O, Yoshiya K, Shiozaki T, Ogura H, Kuwagata Y, et al: Evaluation of posttraumatic venous sinus occlusion with CT venography. J Trauma 66:1002-1007, 2009

14. Greenes DS, Schutzman SA: Infants with isolated skull fracture: what are their clinical characteristics, and do they require hospitalization? Ann Emerg Med 30:253-259, 1997

15. Levi L, Guilburd JN, Linn S, Feinsod M: The association between skull fracture, intracranial pathology and outcome in pediatric head injury. Br J Neurosurg 5:617-625, 1991

16. Masters SJ, McClean PM, Arcarese JS, Brown RF, Campbell JA, Freed HA, et al: Skull x-ray examinations after head trauma. Recommendations by a multidisciplinary panel and validation study. N Engl J Med 316:84-91, 1987

17. Mulroy MH, Loyd AM, Frush DP, Verla TG, Myers BS, Bass $\mathrm{CR}$ : Evaluation of pediatric skull fracture imaging techniques. Forensic Sci Int 214:167-172, 2012

18. Muñoz-Sánchez MA, Murillo-Cabezas F, Cayuela A, FloresCordero JM, Rincón-Ferrari MD, Amaya-Villar R, et al: The significance of skull fracture in mild head trauma differs between children and adults. Childs Nerv Syst 21:128-132, 2005

19. Orman G, Tekes A, Poretti A, Robertson C, Huisman TA: Posttraumatic carotid artery dissection in children: not to be missed! J Neuroimaging 24:467-472, 2014

20. Ratilal BO, Costa J, Pappamikail L, Sampaio C: Antibiotic prophylaxis for preventing meningitis in patients with basilar skull fractures. Cochrane Database Syst Rev 4:CD004884, 2015

21. Rivkin MA, Saraiya PV, Woodrow SI: Sinovenous thrombosis associated with skull fracture in the setting of blunt head trauma. Acta Neurochir (Wien) 156:999-1007, 2014

22. Simon B, Letourneau P, Vitorino E, McCall J: Pediatric minor head trauma: indications for computed tomographic scanning revisited. J Trauma 51:231-238, 2001

23. Sonig A, Thakur JD, Chittiboina P, Khan IS, Nanda A: Is posttraumatic cerebrospinal fluid fistula a predictor of posttraumatic meningitis? A US Nationwide Inpatient Sample database study. Neurosurg Focus 32(6):E4, 2012

24. Stiefel D, Eich G, Sacher P: Posttraumatic dural sinus thrombosis in children. Eur J Pediatr Surg 10:41-44, 2000

25. Taha JM, Crone KR, Berger TS, Becket WW, Prenger EC: Sigmoid sinus thrombosis after closed head injury in children. Neurosurgery 32:541-546, 1993

\section{Disclosures}

The authors report no conflict of interest concerning the materials or methods used in this study or the findings specified in this paper.

\section{Author Contributions}

Conception and design: both authors. Acquisition of data: Adepoju. Analysis and interpretation of data: Adepoju. Drafting the article: Adepoju. Critically revising the article: both authors. Reviewed submitted version of manuscript: Adepoju. Approved the final version of the manuscript on behalf of both authors: Adamo. Statistical analysis: Adepoju. Study supervision: Adamo.

\section{Correspondence}

Matthew A. Adamo, Albany Medical Center, Department of Neurosurgery, 47 New Scotland Ave., MC-10, Albany, NY 12208. email: adamom@mail.amc.edu. 